\title{
Cerebral net exchange of large neutral amino acids after lipopolysaccharide infusion in healthy humans
}

\author{
Ronan MG Berg ${ }^{*}$, Sarah Taudorf ${ }^{1}$, Damian M Bailey² ${ }^{2}$ Carsten Lundby ${ }^{3}$, Fin Stolze Larsen ${ }^{4}$, \\ Bente Klarlund Pedersen ${ }^{1,3}$, Kirsten Møller ${ }^{1,5}$
}

\begin{abstract}
Introduction: Alterations in circulating large neutral amino acids (LNAAs), leading to a decrease in the plasma ratio between branched-chain and aromatic amino acids (BCAA/AAA ratio), may be involved in sepsis-associated encephalopathy. We hypothesised that a decrease in the BCAA/AAA ratio occurs along with a net cerebral influx of the neurotoxic AAA phenylalanine in a human experimental model of systemic inflammation.

Methods: The BCAA/AAA ratio, the cerebral delivery, and net exchange of LNAAs and ammonia were measured before and 1 hour after a 4-hour intravenous infusion of Escherichia coli lipopolysaccharide (LPS) in 12 healthy young men.

Results: LPS induced systemic inflammation, reduced the BCAA/AAA ratio, increased the cerebral delivery and unidirectional influx of phenylalanine, and abolished the net cerebral influx of the BCAAs leucine and isoleucine. Furthermore, a net cerebral efflux of glutamine, which was independent of the cerebral net exchange of ammonia, was present after LPS infusion.

Conclusions: Systemic inflammation may affect brain function by reducing the BCAA/AAA ratio, thereby changing the cerebral net exchange of LNAAs.
\end{abstract}

\section{Introduction}

Sepsis-associated encephalopathy (SAE) is often one of the first manifestations of sepsis [1] and is associated with an adverse outcome [2,3]. The pathogenesis of SAE is largely unknown, although several potential mechanisms have been investigated, including cerebral blood flow $(\mathrm{CBF})$ and metabolic alterations, intracranial hypertension, cerebral edema, disruption of the blood-brain barrier (BBB), neuronal degeneration, and abnormal neurotransmitter composition [4].

Sepsis is characterized by increased peripheral protein breakdown, notably in skeletal muscle $[5,6]$, and hepatic synthesis of acute-phase reactants; the ensuing alterations in plasma amino acids may play a key role in SAE. Thus, the plasma ratio between branchedchain and aromatic amino acids (BCAAs and AAAs,

\footnotetext{
* Correspondence: ronan@dadlnet.dk

${ }^{1}$ Centre of Inflammation and Metabolism, Department of Infectious Diseases, Rigshospitalet, Blegdamsvej 9, 2100 Copenhagen, Denmark Denmark
}

respectively) decreases, because the BCAAs are rapidly used in the liver, whereas phenylalanine levels increase [7-9]. BCAAs and AAAs belong to the group of large neutral amino acids (LNAAs), which compete for the same saturable carrier across the BBB [10]. Hence, a decrease in the BCAA/AAA ratio theoretically implies either a decreased availability of BCAAs to the brain, or an intracerebral accumulation of AAAs, both of which may profoundly affect neuronal function [11].

At present, neither the physiological implications of alterations in the BCAA/AAA ratio nor the effects of systemic inflammation on the cerebral net exchange of LNAAs has been investigated in humans. Applying a human experimental model of systemic inflammation, we hypothesised that the BCAA/AAA ratio decreases with a concurrent net cerebral influx of the neurotoxic AAA phenylalanine, and that this attenuates the net cerebral influx of BCAAs.

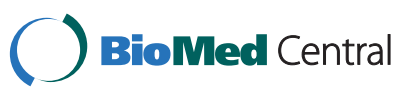




\section{Materials and methods}

Twelve healthy male volunteers aged 20 to 33 (median, 26) years participated in the study after providing oral and written informed consent. All had an unremarkable medical history, with no signs of infection within 4 weeks ahead of the trial day, and none took regular medication. Before inclusion, volunteers underwent a thorough physical examination; a 12-lead electrocardiogram (ECG) was obtained, and standard biochemical tests were performed; all tests were normal. The study was approved by the Scientific Ethical Committee of Copenhagen and Frederiksberg Municipalities, Denmark (file number (KF) 01 290011) and was performed in accordance with the Helsinki Declaration.

Volunteers reported to the laboratory at 7.00 a.m. after an overnight fast and were placed in bed. They were subsequently catheterized with antecubital catheters bilaterally (for saline and lipopolysaccharide (LPS), respectively), a peripheral arterial line and a jugular bulb catheter, of which the two latter were inserted by using local anesthesia with lidocaine. The jugular bulb catheter was inserted into the right internal jugular vein with the tip pointing cranially and by using ultrasound guidance. Correct placement in the jugular bulb was ascertained by feeling a resistance to further advancement of the catheter, as well as the volunteer hearing a purl during a bolus injection of saline; $x$-ray confirmation was not used. One of the authors (KM) inserted all catheters, including the jugular bulb catheters. After catheter insertion, the volunteer rested in the supine position with slight head elevation for 30 minutes before measurements. Heart rate (via a three-lead ECG), blood pressure, and capillary oxygen saturation were continuously monitored. Volunteers were discharged from the unit after 12 hours after removal of catheters and a light meal. No complications occurred.

\section{Study design}

After an overnight fast, subjects were catheterized, and CBF measurements and paired arterio-jugular venous blood samples were obtained at baseline and after a 4-hour continuous intravenous infusion of purified Escherichia coli LPS (infusion rate, $0.075 \mathrm{ng} / \mathrm{kg} / \mathrm{h}$; total dose, $0.3 \mathrm{ng} / \mathrm{kg}$ ); Batch G2 B274, US Pharmacopeial Convention, Rockville, MD, USA). In this model, plasma tumor necrosis factor (TNF)- $\alpha$ peaks at approximately 1 hour after cessation of infusion [12], at which time the second CBF measurement was performed. CBF was determined by means of the Kety-Schmidt technique, as described elsewhere [13].

\section{Blood gases, $\mathrm{pH}$, haemoglobin, and glucose}

Arterial and jugular oxygen tension $\left(\mathrm{PO}_{2}\right)$, carbon dioxide tension $\left(\mathrm{PCO}_{2}\right), \mathrm{pH}$, plasma glucose, and hemoglobin were determined on a blood-gas analyser (ABL 605, Radiometer, Brønshøj, Denmark). For the subsequent calculation of cerebral metabolic rates (CMRs), arterial and jugular venous $\mathrm{PO}_{2}$ and plasma glucose were converted to whole-blood oxygen and glucose content, respectively. The oxygen content $\left(\mathrm{C}_{\mathrm{x}} \mathrm{O}_{2}\right)$ in arterial and jugular venous whole blood was calculated as

$$
\mathrm{C}_{\mathrm{x}} \mathrm{O}_{2}=\mathrm{SO}_{2} \times \mathrm{Hgb}+\mathrm{PO}_{2} \times 0.01
$$

in which $\mathrm{SO}_{2}$ is the oxygen-saturation fraction and $\mathrm{Hgb}$ is the concentration of hemoglobin. Whole-blood glucose was calculated as

Whole blood glucose $=0.75+(0.88 \times$ plasma glucose $)-(2 \times[$ hematocrit in $\%] / 100)$

\section{Amino acids}

Because the plasma and whole-blood concentrations for large neutral amino acids are the same in humans $[14,15]$ and because separation of amino acids is difficult in whole blood, concentrations were determined in plasma, although the exchange between brain and blood of amino acids takes place from both plasma and red blood cells $[14,16]$.

Paired blood samples were simultaneously drawn from the radial artery and the jugular vein after each CBF measurement. The blood was immediately transferred to chilled, heparinized glass tubes, placed on ice, and allowed to equilibrate for 10 minutes. After this, they were centrifuged at $4^{\circ} \mathrm{C}, 3,600 \mathrm{rpm}$, for 15 minutes. The resultant heparinized plasma was precipitated with sulfosalicylic acid (6\%) containing the internal standard for the analysis, norleucine. Samples were then placed on ice for 15 minutes, after which they were centrifuged at $4^{\circ} \mathrm{C}, 3,000 \mathrm{rpm}$ for 30 minutes. With this approach, the amino acid concentration of plasma and red blood cells is fully equilibrated, so that the plasma concentration of a given large neutral amino acid can be considered identical to the whole-blood concentration [17]. Accordingly, the plasma concentrations of amino acids at baseline, measured in the present study, were comparable to whole-blood concentrations of amino acids in humans reported previously [17]. The supernatant was frozen and stored at $-80^{\circ} \mathrm{C}$ until analysis.

LNAAs (phenylalanine, tryptophan, tyrosine, valine, leucine, isoleucine, methionine, histidine, threonine, and glutamine) were separated by a single-column gradient lithium cation-exchange high-performance liquid chromatography with fluorescence detection (Waters HPLC system, Milford, MA), by using post-column derivatization with $o$-phthalaldehyde-mercaptoethanol [18]. The 
coefficient of variation for all amino acid measurements is less than $5 \%$ in this setup.

\section{Ammonia}

To explicate whether a putative cerebral glutamine efflux depended on a cerebral influx of ammonia, the cerebral delivery and net exchange of ammonia were evaluated. The term "ammonia" is used here to depict the total of the charged $\left(\mathrm{NH}_{4}{ }^{+}\right)$and uncharged $\left(\mathrm{NH}_{3}\right)$ species.

Immediately after each CBF measurement, paired blood samples from the radial artery and the jugular vein were simultaneously drawn into EDTA tubes and placed on ice. Within 30 minutes, they were centrifuged at $4^{\circ} \mathrm{C}, 3,600 \mathrm{rpm}$ for 15 minutes; plasma was stored at $-80^{\circ} \mathrm{C}$. The plasma concentration of ammonia was determined by use of microdiffusion, quantitation by reaction with bromophenol blue, and spectrophotometry at 600 nm (Kodak Ektachem 700 Analyzer, Clinical Chemistry Slide; Eastman Kodak Co., Rochester, NY, USA) at the Department of Clinical Biochemistry, Rigshospitalet. In this assay, $\mathrm{NH}_{4}{ }^{+}$, which represents more than $98 \%$ of ammonia in blood under normal physiologic conditions [19], is directly measured. Any $\mathrm{NH}_{3}$ in the sample is converted to $\mathrm{NH}_{4}{ }^{+}$during the course of the assay; in effect, total ammonia $\left(\mathrm{NH}_{4}{ }^{+}+\mathrm{NH}_{3}\right)$ is quantitated. The range of the assay is 6 to $587 \mu \mathrm{mol} / \mathrm{L}$, and internal validation revealed a coefficient of variation of $5 \%$ for values greater than $60 \mu \mathrm{mol} / \mathrm{L}$ and of $11 \%$ for values less than this. The whole-blood ammonia concentration was calculated by Conn's formula [20]:

$$
[\mathrm{NH}]_{\text {whole blood }}=\frac{[\mathrm{NH}]_{\text {plasma }}+31}{0.915}
$$

and converted from $\mu \mathrm{g}$ per $100 \mathrm{~mL}$ into $\mu \mathrm{mol} / \mathrm{L}$.

\section{Markers of inflammation}

White blood cell and platelet counts were analyzed with standard laboratory methods. The plasma concentration of TNF- $\alpha$ was measured by using ELISA (R\&D Systems, Minneapolis, MN, USA). Plasma was obtained by centrifuging whole blood in EDTA-containing tubes at $3,600 \mathrm{rpm}$ at $4^{\circ} \mathrm{C}$ for 15 minutes and was kept at $-80^{\circ} \mathrm{C}$ until analysis. Samples were analyzed in duplicate, and mean concentrations were calculated. Interassay variability (CV) was assessed by using two internal controls (human plasma); one in the lower end of the standard curve ("low," range 0.86 to 1.35 $\mathrm{ng} / \mathrm{L}$ ), and one in the upper end of the standard curve ("high", range 4.32 to $5.26 \mathrm{ng} / \mathrm{L}$ ), as the variability differs throughout the standard curve. Interassay CVs were $32.9 \%$ for "low" and $12 \%$ for "high" TNF- $\alpha$. The
TNF- $\alpha$ detection limit is $0.12 \mathrm{ng} / \mathrm{L}$, according to the manufacturer.

\section{Calculations}

The BCAA/AAA ratio was calculated as the ratio between the arterial plasma concentrations of the BCAAs valine, leucine and isoleucine and the AAAs phenylalanine and tyrosine[21]:

$$
\text { BCAA } / \text { AAA ratio }=\frac{[\text { valine }]+[\text { leucine }]+[\text { isoleucine }]}{[\text { phenylalanine }]+[\text { tyrosine }]} .
$$

The cerebral delivery of a given LNAA was calculated as the product of the arterial concentration and CBF. Cerebral net exchange (unidirectional cerebral influx unidirectional cerebral efflux) values of LNAAs and the CMR of oxygen $\left(\mathrm{CMRO}_{2}\right)$ and glucose $\left(\mathrm{CMR}_{\mathrm{glc}}\right)$ were calculated according to the Fick principle [22]:

$$
\mathrm{J}_{\mathrm{x}}=\mathrm{CBF} \times \mathrm{a}-\mathrm{jvD}_{\mathrm{x}}
$$

in which $\mathrm{J}_{\mathrm{x}}$ designates the net flux (that is, the cerebral net exchange or CMR) of a given substance $x$; a$\mathrm{jvD}_{\mathrm{x}}$ depicts the arterio-jugular venous concentration difference of $x$ in whole blood. By convention, a positive value of $\mathrm{J}_{\mathrm{x}}$ signifies a net influx (uptake) of $\mathrm{x}$, whereas a negative value indicates a net efflux (release) [22].

Given that the BBB transport of a substance can be described accurately by means of a single-membrane model in which the cerebrovascular endothelium behaves as a single membrane, which is the case for LNAAs [23], the unidirectional cerebral influx of phenylalanine $\left(\mathrm{J}_{\text {in, Phe }}\right)$ can be calculated

$$
\mathrm{J}_{\text {in, } \mathrm{Phe}}=\mathrm{PS}_{1} \times[\text { phenylalanine }]
$$

where $\mathrm{PS}_{1}$ is the permeability-surface area product of phenylalanine from the capillary into the brain interstitial space. Because the kinetic constants for the transfer of phenylalanine from blood to brain have been estimated in humans in vivo [24], and have been found to be similar to values obtained by direct measurements on human brain capillaries after death [25], $\mathrm{PS}_{1}$ can be estimated by means of the Michaelis-Menten equation:

$$
\mathrm{PS}_{1}=\frac{\mathrm{V}_{\text {max }}}{\mathrm{K}_{\mathrm{m}}+[\text { phenylalanine }]}+\mathrm{K}_{\mathrm{D}}
$$

In the present context, the maximum transport velocity, $\mathrm{V}_{\text {max }}$, was assumed to be $46.7 \mathrm{nmol} / \mathrm{g} / \mathrm{min}$, the apparent Michaelis-Menten constant, $K_{\mathrm{m}}$, was assumed to be $0.328 \mathrm{mmol} / \mathrm{L}$, and $K_{\mathrm{D}}$, the nonsaturable diffusion constant, was assumed to be $0.01 \mathrm{ml} / \mathrm{g} / \mathrm{min}$ [24]. 


\section{Statistics}

Parametric methods were applied throughout by using SAS statistical software, version 9.1. Thus, all analyses were performed as paired-samples $t$ tests, before and after LPS infusion, to detect an effect of the intervention, and between arterial and jugular venous concentrations at a given time point to determine whether a calculated cerebral net exchange value was different from 0 , that is, whether a cerebral influx or efflux was present. Data are presented as mean $(95 \% \mathrm{CI})$ or as geometric mean $(95 \% \mathrm{CI})$ in case data had to be log-transformed to achieve normality. Significance was established at $P<0.05$.

\section{Results}

LPS infusion was associated with a pronounced inflammatory response; immunologic variables are summarized in Table 1. CBF remained unchanged (baseline, 77 (55101) $\mathrm{mL} / 100 \mathrm{~g} / \mathrm{min}$; LPS, 79 (56-109) $\mathrm{mL} / 100 \mathrm{~g} / \mathrm{min}$; NS). A mild hyperventilatory response with a decrease in arterial $\mathrm{PCO}_{2}$ (baseline, 44.0 (42.5-45.5) $\mathrm{mmHg}$; LPS, 38.8 (36.0-41.6) $\mathrm{mmHg} ; P<0.01)$, and an increase in pH (baseline, 7.39 (7.38-7.40); LPS, 7.42 (7.39-7.44); $P<$ $0.05)$ was evident after LPS infusion. $\mathrm{CMRO}_{2}$ increased slightly (baseline, 1.9 (1.7-2.2) $\mu \mathrm{mol} / \mathrm{g} / \mathrm{min}$; LPS, 2.3 (2.0 - 2.6) $\mu \mathrm{mol} / \mathrm{g} / \mathrm{min} ; P<0.05)$, whereas $C M R_{\text {glc }}$ was unaffected (baseline, 0.36 (0.31-0.40] $\mu \mathrm{mol} / \mathrm{g} / \mathrm{min}$; LPS, 0.39 (0.34-0.44) $\mu \mathrm{mol} / \mathrm{g} / \mathrm{min}$; NS). Some volunteers dozed intermittently but remained easily rousable and alert

Table 1 Markers of inflammation and large neutral amino acids

\begin{tabular}{lll}
\hline & Baseline & LPS \\
\hline Temperature $\left({ }^{\circ} \mathrm{C}\right)$ & $36.3(36.0-36.6)$ & $38.0(37.6-38.6) \neq \neq$ \\
Total white blood cells $\left(10^{9} / \mathrm{L}\right)$ & $5.0(4.5-5.5)$ & $9.0(8.0-10.2) \neq \neq$ \\
Neutrophils $\left(10^{9} / \mathrm{L}\right)$ & $2.7(2.3-3.1)$ & $7.6(6.6-8.7) \neq \neq$ \\
Lymphocytes $\left(10^{9} / \mathrm{L}\right)$ & $1.5(1.3-1.8)$ & $0.8(0.6-1.0) \neq \neq$ \\
TNF- $\alpha(\mathrm{ng} / \mathrm{L})$ & $0.9(0.5-1.4)$ & $10.4(8.7-12.4) \neq \neq$ \\
\hline BCAA/AAA ratio & $5.2(4.7-5.7)$ & $4.9(4.4-5.3)+\dagger$ \\
\hline Phenylalanine $(\mu \mathrm{mol} / \mathrm{L})$ & $36(32-41)$ & $41(38-44)+\dagger$ \\
Tryptophan $(\mu \mathrm{mol} / \mathrm{L})$ & $34(31-38)$ & $28(25-32)+\dagger$ \\
Tyrosine $(\mu \mathrm{mol} / \mathrm{L})$ & $41(35-47)$ & $34(31-39) \dagger$ \\
Valine $(\mu \mathrm{mol} / \mathrm{L})$ & $224(201-247)$ & $200(185-214)+\dagger$ \\
Leucine $(\mu \mathrm{mol} / \mathrm{L})$ & $113(101-26)$ & $104(95-112) \dagger$ \\
Isoleucine $(\mu \mathrm{mol} / \mathrm{L})$ & $59(53-60)$ & $57(54-62)$ \\
Methionine $(\mu \mathrm{mol} / \mathrm{L})$ & $14(13-15)$ & $9(8-10) \neq \neq$ \\
Histidine $(\mu \mathrm{mol} / \mathrm{L})$ & $74(70-78)$ & $58(52-63) \neq \neq$ \\
Threonine $(\mu \mathrm{mol} / \mathrm{L})$ & $102(95-109)$ & $74(66-82) \neq \neq$ \\
Glutamine $(\mu \mathrm{mol} / \mathrm{L})$ & $613(556-669)$ & $449(411-486) \neq \neq$ \\
\hline AAA &
\end{tabular}

AAA = aromatic amino acid; BCAA = branched-chain amino acid, LPS = lipopolysaccharide; TNF- $\alpha$ : tumor necrosis factor $\alpha$. Different from baseline: $\dagger P<0.05 ;+\uparrow P<0.01 ; \neq \neq P<0.0001$. when awakened and were fully awake during measurements; no overt signs of encephalopathy occurred.

LPS infusion increased plasma phenylalanine and decreased the concentration of all other LNAAs except isoleucine (Table 1), with a concurrent reduction in the BCAA/AAA ratio (baseline, 5.2 (4.7-5.7); LPS, 4.9 (4.45.3); Figure 1). Both the cerebral delivery (Table 2) and the unidirectional cerebral influx of phenylalanine increased (baseline, 8.3 (6.7-9.9) $\mathrm{nmol} / \mathrm{g} / \mathrm{min}$; LPS, 9.2 (8.9-10.4) nmol/g/min; Figure 2), whereas its cerebral net exchange was unchanged (Table 3 ). Furthermore, a net cerebral influx observed at baseline for leucine and isoleucine was abolished after LPS infusion (Table 3). At baseline, a net cerebral influx of methionine was present; this was converted to a net cerebral efflux after LPS infusion (Table 3). Furthermore, a net cerebral efflux of glutamine that was not observed at baseline was present after LPS infusion (Table 3). There was no effect of LPS infusion on the arterial whole-blood concentration of ammonia (baseline, 78 (72-84] $\mu \mathrm{mol} / \mathrm{L}$; LPS, 69 (61-76) $\mu \mathrm{mol} / \mathrm{L}$; NS). The cerebral net exchange of ammonia did not differ from 0 at any time and was unaffected by LPS infusion (baseline, 139 ([-70] - 348) $\mathrm{nmol} / 100 \mathrm{~g} / \mathrm{min}$; LPS, -98 ([-618] - 422) nmol/100 g/ min; NS).

\section{Discussion}

The present study is the first to investigate the physiological impact of a decline in the BCAA/AAA ratio after a standardized systemic inflammatory stimulus in humans. In this study, systemic inflammation with an increase in temperature, total white blood cell count, neutrophil count, and plasma TNF- $\alpha$ was associated with a decline in the BCAA/AAA ratio, mainly because of an increase in the arterial concentration of the neurotoxic AAA phenylalanine. A concordant increase in the cerebral delivery and unidirectional cerebral influx of phenylalanine was present during systemic inflammation; this was accompanied by an abolished net cerebral influx of the BCAAs leucine and isoleucine, as well as a cerebral efflux of glutamine. Assuming that the measured cerebral net exchange values are representative for the entire period after LPS infusion, the present findings furthermore indicate that the brain does not contribute to the depletion of glutamine and BCAAs from the circulation during systemic inflammation.

A decrease in the BCAA/AAA ratio was previously demonstrated in patients with sepsis, and this appears to be related to the occurrence of encephalopathy [7-9]. Although the cerebral oxidative metabolism was largely intact, and, as expected, no overt signs of SAE occurred in the subjects, the present human experimental model of sepsis may clarify some underlying concept in the cerebral pathophysiology of sepsis. A decline in the 


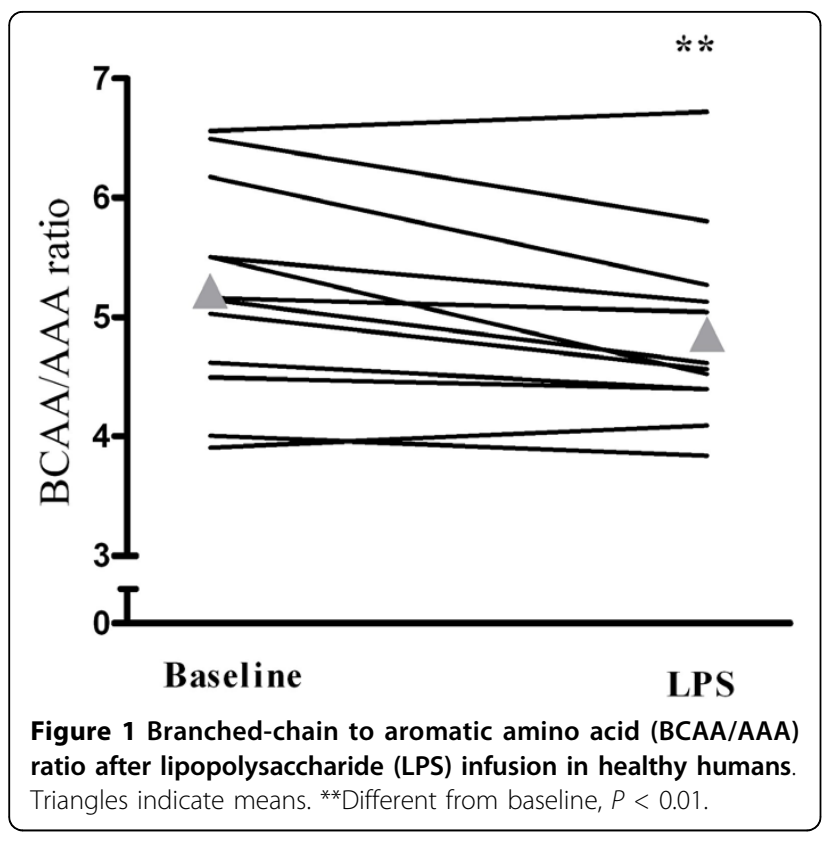

BCAA/AAA ratio was evident after LPS infusion, and this was associated with a remarkable increase in the estimated unidirectional influx of phenylalanine. Thus, if it is assumed that the kinetic constants for phenylalanine transfer across the BBB are not affected by the LPS challenge, the present study provides direct evidence that links the alterations in the BCAA/AAA ratio with changes in the brain's amino acid content in the context of systemic inflammation. Because we did not detect any changes in the cerebral net exchange of phenylalanine, our findings furthermore imply that a new steady state, with elevated phenylalanine levels in the cerebral interstitial fluid, had been established before the second measurement [23]. Previous studies demonstrated increased cerebrospinal fluid (assumed to be representative of the cerebral interstitial fluid) levels of

Table 2 Cerebral delivery of large neutral amino acids

\begin{tabular}{lll}
\hline Amino acid & $\begin{array}{l}\text { Cerebral delivery } \boldsymbol{\mu m o l} / \\
\mathbf{1 0 0} \mathbf{~ g} / \mathbf{m i n} \text { Baseline }\end{array}$ & $\begin{array}{l}\text { Cerebral delivery } \boldsymbol{\mu m o l} / \\
\mathbf{1 0 0} \mathbf{~} / \mathbf{m i n} \text { LPS }\end{array}$ \\
\hline Phenylalanine & $2.8(2.4-3.2)$ & $3.3(2.9-3.6) \dagger$ \\
Tryptophan & $2.6(2.3-3.0)$ & $2.3(1.9-2.8)$ \\
Tyrosine & $3.1(2.7-3.7)$ & $2.8(2.3-3.2)$ \\
Valine & $17.2(14.3-20.1)$ & $16.2(13.7-18.6)$ \\
Leucine & $8.8(7.1-10.4)$ & $8.4(7.1-9.6)$ \\
Isoleucine & $4.6(3.8-5.3)$ & $4.7(4.0-5.4)$ \\
Methionine & $1.1(1.0-1.2)$ & $0.7(0.6-0.9) \neq \dagger$ \\
Histidine & $5.7(4.9-6.5)$ & $4.6(4.0-5.3) \dagger$ \\
Threonine & $7.7(6.5-9.0)$ & $5.8(4.9-6.9) \dagger \dagger$ \\
Glutamine & $47.3(39.6-55.1)$ & $36.3(30.7-42.0) \dagger \dagger$ \\
\hline
\end{tabular}

LPS = lipopolysaccharide. Different from baseline, $+P<0.05 ;+\uparrow P<0.01$; $\neq \dagger P<0.001$.

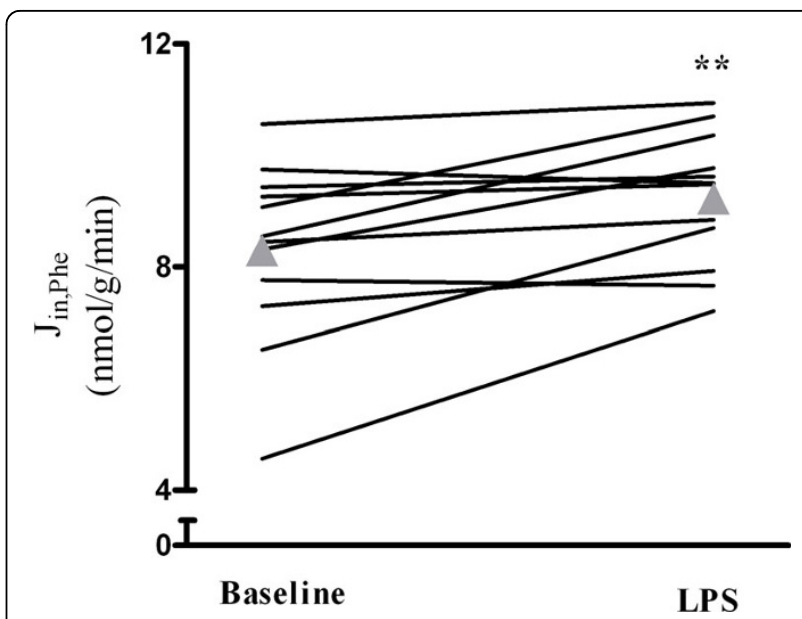

Figure 2 Unidirectional cerebral influx of phenylalanine $\left(J_{i n}\right.$, Phe) after lipopolysaccharide (LPS) infusion in healthy humans.

Triangles indicate means. ${ }^{* *}$ Different from baseline, $P<0.01$.

phenylalanine in patients with sepsis [26], which likely affects central noradrenergic pathways by commencing the generation of "false" neurotransmitters, such as phenylethanolamine [11,27]. An unchanged cerebral net exchange could furthermore involve changes in $\mathrm{BBB}$ function per se through a compensatory increase in the unidirectional cerebral efflux of phenylalanine, a parameter that was not assessed in the present study. This could involve the energy-dependent LNAA transporters on the abluminal membrane of the BBB, which exports phenylalanine from the brain $[28,29]$.

Because AAAs and BCAAs compete for transport across the $B B B$ into the brain by means of the same saturable LNAA carrier [10], the increased arterial phenylalanine levels may furthermore affect cerebral function by reducing the availability of BCAAs to the brain. Concordant with this notion, we found that the observed BCAA/AAA ratio decrease was associated with

Table 3 Cerebral net exchange of large neutral amino acids

\begin{tabular}{lll}
\hline Amino acid & $\begin{array}{l}\text { Cerebral net exchange } \\
\mathbf{n m o l} / \mathbf{1 0 0} \mathbf{~ g / m i n} \text { Baseline }\end{array}$ & $\begin{array}{l}\text { Cerebral net exchange } \\
\mathbf{n m o l} / \mathbf{1 0 0} \mathbf{~ g} / \mathbf{m i n} \text { LPS }\end{array}$ \\
\hline Phenylalanine & $22([-123]-168)$ & $-17([-243]-210)$ \\
Tryptophan & $-62([-251]-125)$ & $-166([-408]-77)$ \\
Tyrosine & $197([-67]-461)$ & $-326([-665]-14)$ \\
Valine & $788(116-1,460)$ & $-331([-1,158]-496)$ \\
Leucine & $650(263-1,037)^{* *}$ & $159([-253]-571)$ \\
Isoleucine & $344(147-541)^{*}$ & $70([-161]-300)$ \\
Methionine & $64(8-12)^{*}$ & $-42.9([-76]-[-9])++^{*}$ \\
Histidine & $126([-162]-415)$ & $-215([-502]-72)$ \\
Threonine & $164([-157]-485]$ & $-355([-765]-56)$ \\
Glutamine & $-305([-241]-1,805)$ & $-3651([-6,038]-[-1,260])^{* *}$ \\
\hline
\end{tabular}

LPS = lipopolysaccharide. Different from baseline, $+\uparrow P<0.01$. Cerebral net exchange different from $0,{ }^{*} P<0.05 ;{ }^{*} P<0.01$. 
an abolished cerebral influx of the BCAAs leucine and isoleucine. Of these two BCAAs, leucine is particularly important in the brain, in which it serves as an amino donor for glutamate synthesis in neurons, thus ensuring sufficiently high intracellular concentrations of glutamate for neuronal glutamatergic signaling [30]; in effect, an abolished cerebral influx of leucine may impair excitatory neurotransmission. Although the available data from previous studies are not unequivocal [31-33], it was previously reported that restoration of the BCAA/ AAA ratio, by means of treatment with BCAA-rich solutions, decreased the intracerebral levels of phenylalanine, reinstated neurotransmitter profiles, and improved symptoms of encephalopathy in clinical and experimental studies of sepsis $[8,27,34]$. The present findings may thus corroborate conceptually important aspects of the cerebral pathophysiology of sepsis in a human-experimental setup, in which inflammation-induced alterations in the BCAA/AAA ratio are accompanied by alterations in the transcerebral exchange kinetics of LNAAs. Conversely, the observed changes could be caused by inflammation-induced alterations in BBB function.

In the present study, LPS infusion was found to instigate a decrease in the arterial glutamine levels, and a cerebral glutamine efflux accompanied this. The former has repeatedly been demonstrated, both in clinical and experimental studies of sepsis $[5,6,35,36]$; the latter has been described in patients with fulminant hepatic failure [17], but has not previously been documented in sepsis. This cerebral efflux likely reflects elevated cerebrospinal fluid glutamine, which has been described in patients with SAE [37].

The cerebral glutamine efflux after LPS infusion was not found to be associated with any changes in the cerebral net exchange of ammonia, which is normally detoxified to glutamine. The classic conception that ammonia merely diffuses across the BBB in its uncharged form $\left(\mathrm{NH}_{3}\right)$ was recently disputed [38,39]; although still controversial, compelling evidence suggests that $\mathrm{NH}_{4}{ }^{+}$, the most abundant form of ammonia in the circulation, is indeed transported across the BBB by means of a specific carrier [19,38]. Neither the arterial levels nor the cerebral delivery of ammonia, the total of $\mathrm{NH}_{4}{ }^{+}$and $\mathrm{NH}_{3}$, was affected in the present model. Consistent with our findings, both circulating and brain levels of ammonia have been reported to be unaffected by LPS infusion in rats [40]. Hyperammonemia has, nevertheless, been demonstrated in some animal models of sepsis [40-42] and may aggravate intracranial hypertension in septic rats [43]. Furthermore, the cerebral net exchange values reported in the present study may be prone to inaccuracy, because of the considerable coefficient of variation of the ammonia measurements in the lower range (11\%). Combined with the relatively low ambient ammonia concentrations, it is possible that any minor arterio-jugular venous concentration differences, which could prompt significant alterations in cerebral net exchange because of the inherently high CBF values, were not detected in our setup. Therefore, we cannot conclusively state that no changes in the cerebral net exchange of ammonia were induced by LPS infusion. In consequence, our findings do not necessarily exclude a pivotal role of ammonia in the pathophysiology of SAE. They do, however, suggest that any putative part played by ammonia in this respect is more likely that of a contributing than of a causative factor, and that a cerebral ammonia uptake is not the solitary cause of the evident cerebral glutamine efflux.

Rather than ammonia detoxification, the cerebral efflux of glutamine after LPS infusion probably reflects increased cerebral proteolysis or a compensatory astrocytic glutamine release, for example, to reduce osmotic stress in the context of cytotoxic edema. As with phenylalanine, an alternative explanation could be the presence of an inflammation-induced increase in the activity in the energy-dependent abluminal LNAA transporters [28], phenomena that are not mutually exclusive. Glutamine supplementation was recently shown to oppose the progressive decline in circulating glutamine levels [35] and to attenuate organ damage in experimental sepsis [36]; however, the impact of glutamine supplementation on brain function and symptoms of encephalopathy in sepsis remains to be elucidated.

Certain limitations exist for the conclusions that can be made from our findings. Based on the methods and findings in the present study, we cannot definitively conclude that the cerebral net exchange of a given amino acid is unaffected in sepsis. The cerebral net exchange values are relatively small at baseline (Table 3), and the clinical impact of LPS infusion is much less than that of full-scale sepsis, although the two scenarios are similar with regard to the cytokine response [44]. It is, therefore, possible that the immune response triggered in this model is not sufficient to cause alterations in the cerebral net exchange of at least some LNAAs of a magnitude that can be detected by the methods applied; the signal-to-noise ratio may be too low, and the duration of systemic inflammation needed for the development of such changes may be longer than that evoked by a 4hour LPS infusion. In addition, the Kety-Schmidt technique exclusively assesses global CBF and metabolism; consequently, potential regional changes remain unveiled. Such changes may in reality be present both during experimental systemic inflammation and in fullscale sepsis. Nonetheless, an immense inflammatory response with biochemical signs of infection was triggered in the present study, and as recently reviewed, a number of confounding factors associated with both 
clinical and animal studies of sepsis are circumvented in the present model [44]. Hence, LPS infusion in humans appears to be valid for human in vivo studies of certain aspects of the pathophysiology of early sepsis.

We did not perform cognitive tests in the volunteers. Thus, possible interrelations between cerebral function and the described alterations in arterial amino acids could not be assessed. It is quite possible that the general malaise experienced by the subjects might have affected cognitive performance, had it been tested thoroughly. However, because all subjects remained alert and responsive during the course of LPS infusion, major cognitive disturbances were unlikely to be present.

\section{Conclusions}

The present study lends further support to the view that LNAAs, particularly phenylalanine, play a pertinent role in the cerebral pathophysiology of sepsis; the arterial levels, cerebral delivery, and unidirectional cerebral influx of phenylalanine increased, whereas the cerebral influx of leucine and isoleucine were abolished, and a cerebral glutamine efflux was induced by LPS infusion in humans. Future studies should address these interrelations and characterize them further, for example through bedside studies on cerebral net exchange, neurotransmitter profiles, BBB function, and the effects of amino acid supplementation on brain function in patients with sepsis.

\section{Key messages}

- LPS infusion induces a systemic inflammatory response and reduces the arterial levels of most LNAAs in humans.

- The systemic inflammatory response is associated with a decrease in the BCAA/AAA ratio, because a reduction in the arterial levels of the BCAAs valine and isoleucine occurs with a concomitant increase in the arterial levels of the neurotoxic AAA phenylalanine.

- The BCAA/AAA ratio decrease is associated with an increase in the cerebral delivery and unidirectional cerebral influx of phenylalanine, an abolished influx of the BCAAs leucine and isoleucine, and an ammonia-independent cerebral efflux of glutamine.

\begin{abstract}
Abbreviations
AAA: Aromatic amino acid; BCAA: branched-chain amino acid; CBF: global cerebral blood flow; CMR: cerebral metabolic rate; ECG: electrocardiogram; Hgb: hemoglobin; J: flux; LNAAs: large neutral amino acids; LPS:

lipopolysaccharide; NH: ammonia; SAE: sepsis-associated encephalopathy.
\end{abstract}

\section{Acknowledgements}

We thank Nine Scherling, Ruth Rousing, Hanne Villumsen, and Annette Jans for their outstanding technical assistance. This study was supported by grants from the Danish National Research Council (file number 22-04-0413, Grant 504-14 and DG 02-512-555), the Copenhagen Hospital Corporation, the Laerdal Foundation, the AP Møller Foundation, the Jensa la Cour Foundation, the Larsen Foundation, the Højmosegaard Foundation, the P. Carl Petersen Foundation, and the Commission of the European Communities (contract no. LSHM-CT-2004-005272 EXGENESIS).

\section{Author details}

${ }^{1}$ Centre of Inflammation and Metabolism, Department of Infectious Diseases, Rigshospitalet, Blegdamsvej 9, 2100 Copenhagen, Denmark. ${ }^{2}$ Neurovascular Research Laboratory, Faculty of Health, Science and Sport, University of Glamorgan, Pontypridd, South Wales CF37 1DL, UK. ${ }^{3}$ Copenhagen Muscle Research Centre, Rigshospitalet, Blegdamsvej 9, 2100 Copenhagen, Denmark. ${ }^{4}$ Department of Hepatology, Rigshospitalet, Blegdamsvej 9, 2100 Copenhagen, Denmark. ${ }^{5}$ Department of Cardiothoracic Anaesthesia and Intensive Care Unit 4131, Rigshospitalet, Blegdamsvej 9, 2100 Copenhagen, Denmark.

\section{Authors' contributions}

RMGB conducted the study, acquired, analyzed, and interpreted the data, performed statistical analyses, and drafted the manuscript. ST, DMB, and $\mathrm{CL}$ conducted the study and acquired and interpreted the data. FSL conducted the amino acid analyses. BKP conceived of and designed the research and handled funding and supervision. KM conceived of and designed the research, conducted the study, acquired, analyzed, and interpreted the data, drafted the manuscript, and handled funding and supervision. All authors made critical revisions and read and approved the final manuscript.

\section{Competing interests}

The authors declare that they have no competing interests.

Received: 27 October 2009 Revised: 16 December 2009

Accepted: 11 February 2010 Published: 11 February 2010

\section{References}

1. Bolton CF, Young GB, Zochodne DW: The neurological complications of sepsis. Ann Neurol 1993, 33:94-100.

2. Sprung $C L$, Peduzzi PN, Shatney $C H$, Schein RM, Wilson MF, Sheagren JN, Hinshaw LB: Impact of encephalopathy on mortality in the sepsis syndrome: the Veterans Administration Systemic Sepsis Cooperative Study Group. Crit Care Med 1990, 18:801-806.

3. Young GB, Bolton CF, Austin TW, Archibald YM, Gonder J, Wells GA: The encephalopathy associated with septic illness. Clin Invest Med 1990, 13:297-304.

4. Papadopoulos MC, Davies DC, Moss RF, Tighe D, Bennett ED: Pathophysiology of septic encephalopathy: a review. Crit Care Med 2000, 28:3019-3024.

5. Gamrin L, Andersson K, Hultman E, Nilsson E, Essen P, Wernerman J: Longitudinal changes of biochemical parameters in muscle during critical illness. Metabolism 1997, 46:756-762.

6. Vesali RF, Klaude M, Rooyackers OE, Tjäder I, Barle H, Wernerman J: Longitudinal pattern of glutamine/glutamate balance across the leg in long-stay intensive care unit patients. Clin Nutr 2002, 21:505-514.

7. Vente JP, von Meyenfeldt MF, van Eijk HM, van Berlo CL, Gouma DJ, Linden van der CJ, Soeters PB: Plasma-amino acid profiles in sepsis and stress. Ann Surg 1989, 209:57-62.

8. Freund HR, Muggia-Sullam M, LaFrance R, Holroyde J, Fischer JE: Regional brain amino acid and neurotransmitter derangements during abdominal sepsis and septic encephalopathy in the rat: the effect of amino acid infusions. Arch Surg 1986, 121:209-216.

9. Basler T, Meier-Hellmann A, Bredle D, Reinhart K: Amino acid imbalance early in septic encephalopathy. Intensive Care Med 2002, 28:293-298.

10. Smith QR, Momma S, Aoyagi M, Rapoport SI: Kinetics of neutral amino acid transport across the blood-brain barrier. J Neurochem 1987, 49:1651-1658.

11. Freund $\mathrm{H}$, Atamian S, Holroyde J, Fischer JE: Plasma amino acids as predictors of the severity and outcome of sepsis. Ann Surg 1979, 190:571-576.

12. Taudorf S, Krabbe KS, Berg RMG, Pedersen BK, Møller K: Human models of low-grade inflammation: bolus versus continuous infusion of endotoxin. Clin Vaccine Immunol 2007, 14:250-255. 
13. Taudorf S, Berg RMG, Bailey DM, Møller K: Cerebral blood flow and oxygen metabolism measured with the Kety-Schmidt method using nitrous oxide. Acta Anaesthesiol Scand 2009, 53:159-167.

14. Felig P, Wahren J, Raf L: Evidence of inter-organ amino-acid transport by blood cells in humans. Proc Natl Acad Sci USA 1973, 70:1775-1779.

15. Hagenfeldt $L$, Arvidsson A: The distribution of amino acids between plasma and erythrocytes. Clin Chim Acta 1980, 100:133-141.

16. Drewes LR, Conway WP, Gilboe DD: Net amino acid transport between plasma and erythrocytes and perfused dog brain. Am J Physiol 1977, 233: E320-E325.

17. Strauss Gl, Knudsen GM, Kondrup J, Møller K, Larsen FS: Cerebral metabolism of ammonia and amino acids in patients with fulminant hepatic failure. Gastroenterology 2001, 121:1109-1119.

18. Møller SE: Quantification of physiological amino acids by gradient ionexchange high-performance liquid chromatography. J Chromatogr 1993 613:223-230.

19. Bosoi $C R$, Rose CF: Identifying the direct effects of ammonia on the brain. Metab Brain Dis 2009, 24:95-102.

20. Conn HO: Studies on the origin and significance of blood ammonia, II: the distribution of ammonia in whole blood, plasma and erythrocytes of man. Yale J Biol Med 1966, 39:38-53.

21. Fischer JE, Funovics JM, Aguirre A, James JH, Keane JM, Wesdorp RI, Yoshimura N, Westman T: The role of plasma amino acids in hepatic encephalopathy. Surgery 1975, 78:276-290.

22. Fick A: Über die Messung des Blutquantums in den Herzventrikeln. Verh Phys Med Ges Würzburg 1870, 2:16.

23. Knudsen GM, Pettigrew KD, Patlak CS, Hertz MM, Paulson OB: Asymmetrical transport of amino acids across the blood-brain barrier in humans. $J$ Cereb Blood Flow Metab 1990, 10:698-706.

24. Knudsen GM, Hasselbalch S, Toft PB, Christensen E, Paulson OB, Lou H: Blood-brain barrier transport of amino acids in healthy controls and in patients with phenylketonuria. J Inherit Metab Dis 1995, 18:653-664.

25. Choi TB, Pardridge WM: Phenylalanine transport at the human bloodbrain barrier: studies with isolated human brain capillaries. J Biol Chem 1986, 261:6536-6541

26. Mizock BA, Sabelli HC, Dubin A, Javaid II, Poulos A, Rackow EC: Septic encephalopathy: evidence for altered phenylalanine metabolism and comparison with hepatic encephalopathy. Arch Intern Med 1990, 150:443-449.

27. Freund HR, Ryan JA Jr, Fischer JE: Amino acid derangements in patients with sepsis: treatment with branched chain amino acid rich infusions. Ann Surg 1978, 188:423-430.

28. O'Kane RL, Hawkins RA: Na+-dependent transport of large neutral amino acids occurs at the abluminal membrane of the blood-brain barrier. Am J Physiol Endocrinol Metab 2003, 285:E1167-E1173.

29. Hawkins RA, O'Kane RL, Simpson IA, Vina JR: Structure of the blood-brain barrier and its role in the transport of amino acids. J Nutr 2006, 136:218S-226S

30. Yudkoff M, Daikhin Y, Nissim I, Horyn O, Luhovyy B, Lazarow A, Nissim I: Brain amino acid requirements and toxicity: the example of leucine. $J$ Nutr 2005, 135:1531S-1538S

31. Basler T, Meier-Hellmann A, Bredle D, Reinhart K: Amino acid imbalance early in septic encephalopathy. Intensive Care Med 2002, 28:293-298.

32. von Meyenfeldt MF, Soeters PB, Vente JP, van Berlo CL, Rouflart MM, de Jong KP, Linden van der CJ, Gouma DJ: Effect of branched chain amino acid enrichment of total parenteral nutrition on nitrogen sparing and clinical outcome of sepsis and trauma: a prospective randomized double blind trial. Br J Surg 1990, 77:924-929.

33. García-de-Lorenzo A, Ortíz-Leyba C, Planas M, Montejo JC, Núñez R, Ordóñez FJ, Aragón C, Jiménez FJ: Parenteral administration of different amounts of branch-chain amino acids in septic patients: clinical and metabolic aspects. Crit Care Med 1997, 25:418-424

34. Freund HR, Muggia-Sullam M, Peiser J, Melamed E: Brain neurotransmitter profile is deranged during sepsis and septic encephalopathy in the rat. $J$ Surg Res 1985, 38:267-271.

35. Andreasen AS, Pedersen-Skovsgaard T, Mortensen $\mathrm{OH}$, van Hall G, Moseley $\mathrm{PL}$, Pedersen BK: The effect of glutamine infusion on the inflammatory response and HSP70 during human experimental endotoxaemia. Crit Care 2009, 13:R7.

36. Oliveira GP, Oliveira MB, Santos RS, Lima LD, Dias CM, Ab' Saber AM Teodoro WR, Capelozzi VL, Gomes RN, Bozza PT, Pelosi P, Rocco PR:
Intravenous glutamine decreases lung and distal organ injury in an experimental model of abdominal sepsis. Crit Care 2009, 13:R74.

37. Mizock BA, Dubin A, Rackow EC, Burke GS: Elevated cerebrospinal fluid glutamine in septic encephalopathy. J Clin Gastroenterol 1989, 11:362-363.

38. Ott $P$, Larsen FS: Blood-brain barrier permeability to ammonia in liver failure: a critical reappraisal. Neurochem Int 2004, 44:185-198.

39. Lockwood AH: Controversies in ammonia metabolism: implications for hepatic encephalopathy. Metab Brain Dis 2007, 22:285-289.

40. Wright G, Davies NA, Shawcross DL, Hodges SJ, Zwingmann C, Brooks HF, Mani AR, Harry D, Stadlbauer V, Zou Z, Williams R, Davies C, Moore KP, Jalan R: Endotoxemia produces coma and brain swelling in bile duct ligated rats. Hepatology 2007, 45:1517-1526.

41. Jeppsson B, Freund HR, Gimmon Z, James JH, von Meyenfeldt MF, Fischer JE: Blood-brain barrier derangement in sepsis: cause of septic encephalopathy?. Am J Surg 1981, 141:136-142.

42. Kadoi $Y$, Saito $S$ : An alteration in the gamma-aminobutyric acid receptor system in experimentally induced septic shock in rats. Crit Care Med 1996, 24:298-305.

43. Pedersen HR, Ring-Larsen H, Olsen NV, Larsen FS: Hyperammonemia acts synergistically with lipopolysaccharide in inducing changes in cerebral hemodynamics in rats anaesthetised with pentobarbital. $J$ Hepatol 2007, 47:245-252.

44. Andreasen AS, Krabbe KS, Krogh-Madsen R, Taudorf S, Pedersen BK, Møller K: Human endotoxemia as a model of systemic inflammation. Cur Med Chem 2008, 15:1697-1705.

\section{doi:10.1186/cc8873}

Cite this article as: Berg et al:: Cerebral net exchange of large neutral amino acids after lipopolysaccharide infusion in healthy humans. Critical Care 2010 14:R16.

\section{Submit your next manuscript to BioMed Central and take full advantage of:}

- Convenient online submission

- Thorough peer review

- No space constraints or color figure charges

- Immediate publication on acceptance

- Inclusion in PubMed, CAS, Scopus and Google Scholar

- Research which is freely available for redistribution
C) Biomed Central 